\title{
Hermenêutica e anti-hermenêutica. Friedrich Schlegel e Schleiermacher
}

\author{
Wilma Patricia Maas ${ }^{1}$
}

Resumo: A fortuna crítica de Friedrich Schlegel é rica em alusões a sua relação com Schleiermacher. Ambos conviveram em Berlim por volta de 1800, época em que Schlegel editava a Athenäum e em que Schleiermacher ainda não escrevera seus principais textos sobre hermenêutica. É possível conceber Friedrich Schlegel como um predecessor de Schleiermacher? $\mathrm{Na}$ tentativa de responder a essa pergunta, vamos nos deter sobre três textos, todos eles publicados na Athenäum: o ensaio sobre Lessing (Über Lessing, 1797), o ensaio sobre o Wilhem Meister de Goethe (Über Goethes Wilhelm Meisters Lehrjahre, 1798) e o ensaio da ininteligibilidade (Über die Unverständlichkeit, 1800).

Palavras-chave: Friedrich Schlegel; Schleiermacher; Hermenêutica

\begin{abstract}
In Friedrich Schlegel's criticism, one can find many references to his relationship to Schleiermacher. Both were closely related by the time they in Berlin around 1800, when Schlegel edited the Athenäum and Schleiermacher had not yet written his most important texts on Hermeneutics. But can we consider Schlegel an early influence on Schleiermacher's thought by that time? In order to answer this question, we will focus on three of Schlegel's essays of that time: Über Lessing (1797), Über Wilhem Meisters Lehrjahre (1798) and Über die Unverständlichkeit (1800).
\end{abstract}

Keywords: Friedrich Schlegel; Schleiermacher; Hermeneutics

Não são poucas as dificuldades que se apresentam ao estudioso que pretenda localizar tópicos apresentados de maneira inequívoca, na obra de Friedrich Schlegel. A

1 Wilma Patricia Maas é professora de Literatura Alemã no Departamento de Letras Modernas e do Programa de Pós-Graduação em Estudos Literários da Faculdade de Ciências e Letras da UNESP Araraquara. E-Mail: pmaas@uol.com.br. Todas as traduções do alemão ao português são de responsabilidade da autora. 
Maas, W. P. - Hermenêutica e anti-hermenêutica

preferência do autor pelo estilo fragmentário e circular, o elogio declarado da contradição, do paradoxo e da ironia, assim como algumas circunstâncias pessoais contribuem para que a crítica especializada ainda hoje se debata com os critérios de comprovação filológica, de modo que ainda hoje, mais de 50 anos depois do início da publicação da edição crítica, permanecem algumas contradições importantes. Uma das mais produtivas é a focalização da relação entre a filologia praticada por Schlegel e a hermenêutica como a entendeu Schleiermacher.

Essa contradição não se restringe apenas a textos entre os quais há uma grande distância temporal, ou seja, às diferenças entre o "jovem Schlegel” e o Schlegel tardio. Entre os textos publicados na Athenäum já se estabelece, com visibilidade, a relação paradoxal entre uma postura que situa Schlegel como uma espécie de fonte de inspiração para o amigo Schleiermacher e ao mesmo tempo como um obscurantista, que praticasse o mal-entendido, a ironia e o paradoxo pelo amor à ininteligibilidade.

A relação entre a hermenêutica moderna e o Primeiro Romantismo Alemão deuse de forma bastante direta. Friedrich Ernst Daniel Schleiermacher, o chamado "pai da hermenêutica moderna", conviveu muito proximamente com os membros do grupo de Jena, principalmente com Friedrich Schlegel, em defesa do qual saiu quando das acusações de obscenidade feitas ao autor de Lucinde (1799), o romance-ensaio de Schlegel. Ora, as circunstâncias pessoais e cronológicas que unem Schleiermacher e Schlegel têm um formidável contraponto no que diz respeito às concepções que um e outro tem da linguagem e das possibilidades de compreensão intersubjetiva.

O pressuposto fundamental da hermenêutica estabelecida por Schleiermacher é, certamente, o da transparência da linguagem, sendo o procedimento hermenêutico o método de interpretação capaz de atingir a verdade do texto, a partir da investigação produtiva de seus pontos aparentemente obscuros (herméticos). Friedrich AsT, representante da hermenêutca da Aufklärung e autor de Grundlinien der Grammatik Hermeneutik und Kritik [Princípios de gramática, hermenêutica e crítica], de 1808, atribuía ao intérprete dos textos da Antigüidade a capacidade de compartilhar da unidade original de todas as coisas no Espírito“. (AST 1808: 168-9). Dessa forma, o intérprete, compartilhando de um "espírito comum" e transhistórico, poderia transpor as fronteiras que separam objeto do sujeito interpretante, ao menos idealmente. Segundo AST, “apenas o que é temporal e exterior (educação, formação, situação geográfica, etc.) 
Maas, W. P. - Hermenêutica e anti-hermenêutica

produz a diferença entre os espíritos” (Id., ibd.). Schleiermacher, que dialogará com Ast em seus Discursos da academia, de 1829, buscará justamente os princípios de uma hermenêutica geral no próprio ato da interpretação. As diferenças, que para seu antecessor Ast são anuladas ou desconsideradas a partir de um conceito idealista de espírito e de reprodução do Todo nas partes, são, para o Schleiermacher maduro, o cerne do ato da interpretação. O procedimento hermenêutico prevê um intercâmbio de diferenças estilísticas e históricas entre intérprete e texto, cujo objetivo final é o estabelecimento de coerência, correspondência e identidade. A interpretação funciona segundo o modelo de pergunta-e-resposta, procedendo segundo os preceitos do círculo hermenêutico, no qual a parte e o todo se interpenetram continuamente, até que se tenha estabelecido uma totalidade semântica articulada.

Depreende-se daí que a hermenêutica geral desenvolvida pelo Schleiermacher pós 1829, que tem justamente na integração das diferenças, assim como na possibilidade de universalidade do entendimento, o pressuposto do ato da interpretação, encontra-se, em seus principais teoremas, em franca oposição ao pensamento filológico, literário e filosófico do jovem Schlegel. A hermenêutica de Schleiermacher compartilha, por exemplo, com o futuro estruturalismo de Saussure a concepção de uma linguagem articulada em níveis, de cuja combinação e substituição de elementos se constrói o sentido. Uma tal concepção é cabalmente desfeita por textos como Über die Unverständlichkeit [Da ininteligibilidade, 1800], ensaio do jovem Schlegel no qual a ironia é o sintoma mais dramático e irrevogável da obscuridade lingüística, e como Monolog [Monólogo, 1798], de Novalis, que antecipa, de maneira espantosa, a crise da referencialidade instalada na lingüística pós-saussureana.

A concepção de linguagem praticada e defendida por F. Schlegel opõe-se ainda a um conceito fundamental para a hermenêutica de Schleiermacher, que tem no trecho obscuro e no equívoco da inteligibilidade [Missverständnis] a fonte de sua metodologia de interpretação. Para Schleiermacher, é exatamente o Missverständnis que pode e deve ser elucidado através dos procedimentos de contextualização lingüística, estilística, histórica e histórico-literária, o que permitirá a completa interpretação e desvendamento do texto. A isso, ScHLEGEl oporá o caráter irrevogavelmente opaco da linguagem do qual a ironia se faz índice: 
Maas, W. P. - Hermenêutica e anti-hermenêutica

O senso comum,que se deixa tão prazerosamente guiar pelo método das etimologias, quando estas se encontram à mão, poderia facilmente chegar à suposição de que a causa da ininteligibilidade reside naquilo que é ininteligível. [...] Eu queria mostrar que a mais pura e a mais sólida ininteligibilidade provém exatamente da ciência e da arte que partem do que é compreensivel e do fazer compreender, da filosofia e da filologia (SCHLEGEL 1967 :362, 364, grifo meu)

O trecho expressa, pelo viés da ironia, o desprezo de Schlegel pelo procedimento hermenêutico do esclarecimento a partir da investigação histórico-filológica do trecho hermético. A par disso, depreende-se sua convicção de que o que parece obscuro a um indivíduo assim lhe parece devido a uma irrevogável e irredutível impossibilidade de comunicação interpessoal. Schlegel destrói, dessa maneira, a crença na possibilidade do processo hermenêutico de elucidação do mal-entendido e do trecho obscuro por meio da identificação dos usos lingüísticos não-familiares, ou seja, por meio da familiarização daquilo que é estranho, pressuposto básico da hermenêutica de Schleiermacher.

Expostas que estão as principais divergências nitidamente existentes entre o pensamento filológico do Schlegel da época da Athenäum e do Schleiermacher maduro, articulador da hermenêutica moderna de base filológica, debruçamo-nos agora sobre uma hipótese freqüentemente mencionada pela fortuna crítica de um e de outro, mas que carece, ainda hoje, de investigação mais acurada. Trata-se da mencionada afinidade entre o pensamento filológico do jovem Schlegel e do primeiro Schleiermacher, que conviveram em Berlim por volta de 1800 e mantiveram intenso intercâmbio de idéias. A despeito das inegáveis diferenças de ambas as concepções de linguagem, é possível conceber Schlegel como um predecessor de Schleiermacher? Na tentativa de responder a essa pergunta, vamos nos deter sobre três textos, todos eles publicados na Athenäum: o ensaio sobre Lessing (Über Lessing, 1797), o ensaio sobre o Wilhem Meister de Goethe (1798) e o ensaio da ininteligibilidade (Über die Unverständlichkeit, 1800).

Já em 1928, Josef KÖRNER atribuía a Schlegel a fundação de uma hermenêutica científica. Gadamer, por sua vez, ao atribuir a Schleiermacher o famoso mote segundo o qual o intérprete "deve compreender um autor melhor do que ele próprio compreende a si mesmo" (GADAMER 1960: 183), curiosamente comprova essa atribuição com um trecho dos Philosophische Lehrjahre [Anos de aprendizado filosófico], de Schlegel, escritos à época da convivência com Schleiermacher em Berlim: 
Maas, W. P. - Hermenêutica e anti-hermenêutica

Para que se possa compreender alguém, é preciso ser mais inteligente do que ele, depois tão inteligente e depois ainda tão estúpido quanto ele. Não basta que se entenda melhor do que o autor entendeu o sentido próprio de uma obra confusa. É preciso também conhecer os princípios da própria confusão, ser capaz de caracterizá-los e construí-los. (SCHLEGEL 1956: 58)

É certamente possível apontar coincidências entre determinados conceitos basilares da hermenêutica moderna tanto em Schlegel quanto em Schleiermacher. Ambos compartilham da compreensão da filologia como arte: "Im Begriff, Beweis, daß die Philologie eine Kunst sei." (Schlegel apud PATsCH 1962: 446) Para a prática da filologia é necessária uma formação em conformidade com a arte ("eine kunstmäßige Ausbildung”) : "A filologia não é um simples composto científico, mas sim um todo. Não um todo lógico, mas um todo técnico" (Ib., ibid.). SCHLEIERMACHER, por usa vez, tem uma concepção lapidar: "A interpretação é arte" ["Das Auslegen ist Kunst."], lê-se nos manuscritos de 1819 (apud PATSCH 1966: 447). Nas anotações de 1809/1810 encontra-se a provável gênese dessa concepção:

\begin{abstract}
A compreensão parte de dois pontos completamente diferentes: a compreensão na linguagem e a compreensão naquele que faz uso dela, o falante. Por causa dessa dupla via do processo de compreensão, a interpretação é uma arte. Nada pode se tornar completo apenas por si mesmo. (SCHLEIERMACHER 1829:138)
\end{abstract}

Schleiermacher também considera a interpretação como uma arte no sentido em que o termo comporta de "técnica", como emprego metódico de regras, capaz de promover a compreensão do texto em toda sua extensão: "A compreensão deve ser buscada e desejada em cada ponto do texto". (SCHLEIERMACHER 1829: 86)

Uma provável identidade intelectual entre ambos poderia ainda ser justificada pela decisão programática, comum ao pensamento do Primeiro Romantismo, de praticar uma "simfilosofia" ["Symphilosophie"] e uma "simpoesia" ["Sympoesie"]. Ainda que Schlegel não tenha desenvolvido uma teoria hermenêutica, tem em comum com Schleiermacher a tarefa da determinação das relações entre filologia e filosofia. Nos termos de PATSCH:

Em Schlegel, não se trata do desenvolvimento de uma teoria hermenêutica, como é o caso em Schleiermacher, mas sim da determinação crítica da relação entre filosofia e filologia, relação essa para a qual o problema da hermenêutica 
Maas, W. P. - Hermenêutica e anti-hermenêutica

parece ser um tema secundário. Entretanto, é exatamente esse questionamento que permitirá que se vislumbre a "virada" romântica da doutrina da compreensão e a respectiva participação que Schleiermacher teve nesse processo. (PATSCH 1966: 445)

Sob a luz da pesquisa atual sobre Schlegel, a primeira parte da primeira da oração pode, sem dúvida alguma, ser mantida. Schlegel não está, de fato, preocupado ou empenhado em desenvolver uma teoria hermenêutica, nem mesmo uma "moderna", "romântica" ou "filológica" teoria hermenêutica. É possível também manter o pressuposto de que faz parte das preocupações do Schlegel de 1800 estabelecer uma visão crítica das relações entre filosofia e filologia, o que se pode reconhecer de maneira nítida no texto da ininteligibilidade. Mas o fato de não haver um ato positivo na direção da construção de uma teoria hermenêutica não significa que esta, como arte da compreensão do discurso do outro, desempenhe um papel secundário. É provável que nesse ponto, e só nesse ponto, resida a verdadeira identidade entre o pensamento de F. Schlegel e Schleiermacher. Ambos estão nitidamente comprometidos com a questão do alcance e das possibilidades da compreensão intersubjetiva. Sob esse aspecto, Schleiermacher irá, de fato, construir seu sistema hermenêutico (ou resgatá-lo, a partir da hermenêutica da Aufklärung), ao passo que Schlegel, sob o viés do paradoxo, do fragmento e da ironia, jamais atuará esse sentido. Seu legado, ao mesmo tempo contemporâneo da construção da hermenêutica moderna, oferece a crítica (e mesmo a "desconstrução") desse edifício filológico ${ }^{2}$.

\section{Da letra ao espírito}

Schlegel e Schleiermacher compartilharão, por volta de 1799, da opinião de que a uma hermenêutica exclusivamente filológica deverá suceder uma hermenêutica do espírito. Em Reden über die Religion [Discursos sobre a religião,1799], é possível identificar duas linhas fundamentais do pensamento de Schleiermacher, que culminarão no deslocamento da hermenêutica da letra para uma hermenêutica do espírito. De maneira surpreendente para o assim chamado fundador da hermenêutica moderna,

2 Fato que o aproxima, a nosso ver, da perspectiva "desconstrucionista" de Paul de Man e do pósestruturalismo em geral. 
Maas, W. P. - Hermenêutica e anti-hermenêutica

Schleiermacher expressa ali a dissociação entre o processo de compreensão da letra e a constituição do sentido filosófico ou religioso:

É com pesar que vejo diariamente o furor da compreensão impedir completamente o surgimento do sentido e como tudo conjura para que o homem permaneça atado ao que é finito e apenas a uma parte muito pequena dele, de modo que o infinito lhe seja levado o mais longe possível dos olhos. Quem é que impede o florescimento da religião? Não os descrentes e os blasfemos, pois, ainda que se comprazam em afirmar que não possuem religião alguma, não impedem o caminho da natureza [...]. Também não aqueles destituídos de moral, como comumente se pensa, pois suas aspirações e sua atuação contrapõem-se a uma força de caráter totalmente diferente dessa; quem impede o florescimento da religião são os entendidos [die Verständigen]. (SCHLEIERMACHER apud HÖRISCH 1988: 24).

É inevitável relembrar aqui o Schlegel do ensaio sobre a ininteligibilidade, para quem "a mais pura e sólida ininteligibilidade provém exatamente da ciência e da arte que partem do compreensível e do fazer compreender, da filosofia e da filologia (SCHLEGEL 1967: $364)$.

Ainda nos mesmos Discursos sobre a religião, SCHLEIERMACHER reitera a descrença no "furor da compreensão": "O principal é que eles [os entendidos] supõemse capazes de entender tudo, e com esse entender eles se deixam enganar completamente em relação ao sentido.“ (apud HÖRISCH 1989: 82)

É preciso ressaltar aqui que as objeções de Schleiermacher nos Discursos sobre a religião estão voltadas especificamente à questão da mediação da palavra divina, uma vez que a própria necessidade de existência de um Vermittler (mediador) torna evidente a aporia que permeia o processo da interpretação religiosa: caso essa "intermediação entre o reino de Deus e o mundo dos homens cessasse", então "compreenderíamos mesmo a mais inaudível das palavras, ao passo que agora, mesmo as mais claras manifestações não escapam ao mal-entendido". (Id., ibd.) Ainda:

Se tudo o que é finito carece da mediação de algo superior para não se distanciar cada vez mais do universo [...], mantendo sua relação com o universo e com a consciência da existência dele: então é impossível que esse mediador, que não pode necessitar ele mesmo de mediação, seja simplesmente finito; ele deve pertencer às duas instâncias, compartilhar da natureza do divino e também da esfera sensível compartilhada pelo finito. (SCHLEIERMACHER apud HÖRISCH 1989: 26). 
Maas, W. P. - Hermenêutica e anti-hermenêutica

A partir do reconhecimento dessa aporia, Schleiermacher chega àquele que será o conceito fundamental de sua hermenêutica futura: o conceito de espírito, elevado a princípio fundamental do processo de interpretação, que dá vida ao que está morto na letra. O reconhecimento do esquema paulino da letra morta e que mata, frente ao espírito que vive e vivifica, é primordialmente hermenêutico, e virá a constituir o núcleo e fundamento da futura hermenêutica de Schleiermacher.

Assim, estritamente anti-hermenêuticas são apenas as observações sobre "o furor da compreensão" [Wut des Verstehens], que a tudo torna homogêneo e que em certa medida eleva o homem ao mesmo grau de Deus.

Mais tarde, nos Akademiereden [Discursos à Academia, 1829] Schleiermacher é tomado ele mesmo pelo furor da compreensão. $O$ elogio da compreensão homogeneizante e totalizadora pode ser depreendido a partir de um ponto de vista que considera a tarefa da hermenêutica (referida aqui a Ast e à filologia clássica) como sendo a de "nos conduzir ao pico mais elevado da unidade do espírito" (SCHLEIERMACHER 1977: 315). O procedimento hermenêutico prescreve a familiarização daquilo que é estranho: "[das] Fremde [wird] in Eignes verwandelt." (Id., ibid. 1977: 315) : o "negócio da compreensão e da interpretação é [...] um todo que se desenvolve contínua e gradativamente [...], é o encontro gradual do espírito pensante consigo mesmo“ (SCHLEIERMACHER 1977: 327-328s). Até aqui, é possível afirmar que F. Schlegel e Schleiermacher percorreram, em boa parte de seu caminho, trajetórias comuns, principalmente no que diz respeito à predominância da hermenêutica do espírito sobre a hermenêutica da letra, assim como à própria desconfiança (em Schleiermacher, apenas pontual) quanto à homogeneização do processo interpretativo. Entretanto, o pensamento de Schleiermacher seguirá incólume em direção a uma "arte da interpretação" baseada na segmentação dos níveis da linguagem (como se verá posteriormente em Saussure), ao passo que Schlegel encontrará, na ironia, o elemento desestabilizador de todo edifício hermenêutico, uma vez que nega ao texto sua condição mínima de operação, que é a de ser considerado como "sério", "válido" ou "lógico".

Se tomarmos como corpus principal o ensaio da ininteligibilidade, são muitas as passagens em que a letra é considerada antes fonte de equívoco do que de potencial esclarecimento. $\mathrm{O}$ próprio procedimento hermenêutico de base filológica é negado. 
Maas, W. P. - Hermenêutica e anti-hermenêutica

Schlegel propõe em seu lugar a "dedução de um novo leitor", criado em tempo real pelo próprio texto e seu autor:

Quanto a mim, não posso suportar a falta de entendimento, mesmo a falta de entendimento dos desentendidos, mas menos ainda a falta de entendimento dos entendidos ${ }^{3}$. Por conta disso, há muito tomei a decisão de entabular um diálogo com o leitor a respeito dessa matéria, construindo, imediatamente sob o seu nariz, um novo leitor, de acordo com minhas concepções, ou mesmo deduzindoo, se assim me parecer necessário. (SCHLEGEL 1967: 363-364)

Compara-se a seguir com o seguinte trecho de Schleiermacher:

Até aqui está claro que a explicação da palavra e das coisas ainda não é interpretação, mas sim apenas um elemento dela, e que a hermenêutica começa apenas com a determinação do sentido, por meio desse mesmo elemento. Da mesma forma está claro que a determinação do sentido jamais será correta se ela não suportar a prova do espírito do escritor, assim como a prova da Antiguiidade. Pois ninguém fala ou escreve algo contrário a seu próprio espírito, a não ser em um estado de perturbação mental. (in FRANK 1989 :22, grifo meu)

Esse estado de "perturbação mental" ["gestörter Gemützustand”] aludido por Schleiermacher poderia bem ser o diagnóstico (e, em Hegel, trata-se mesmo disso) dado pelo senso comum ["gesunder Menschenverstand"] frente a um texto como o ensaio da ininteligibilidade, discurso inacessível até mesmo à hermenêutica do espírito congenial. Isso quer dizer que, ainda que Schlegel e Schleiermacher compartilhem da opinião que subordina a letra ao espírito, ainda que ambos concordem com o princípio da "letra morta", a incompreensibilidade, no texto schlegeliano, é radical e refratária a qualquer abordagem semiótica hierárquica e dualista.

Em Schleiermacher, a hermenêutica do espírito apóia-se claramente no pressuposto da congenialidade e da intenção "séria" do autor, pois ninguém dirá ou escreverá algo contrário a seu espírito a não ser em um estado de perturbação mental. Schlegel vai compartilhar desses pressupostos reconfigurando-os de forma radical: a congenialidade em Schlegel dá-se apenas por força da "dedução do leitor ideal”, de sua construção performativa "sob o nariz do leitor" histórico, ao passo que o pressuposto da 
Maas, W. P. - Hermenêutica e anti-hermenêutica

seriedade das intenções do autor será abalado e reformado pela "mais livre de todas as licenças, pela ironia".

A complexidade das relações entre Schlegel e a hermenêutica não se esgota aí. Há textos de Schlegel que muitos consideram o ponto alto do procedimento hermenêutico, como o ensaio sobre Lessing e a crítica sobre o Meister de Goethe, o famoso Übermeister.

\section{ensaio sobre Lessing}

O ensaio Über Lessing [Sobre Lessing] é um dos documentos mais citados quando se pretende comprovar a existência de um método hermenêutico em Schlegel. Ali, Schlegel justifica a escolha de seu objeto reconhecendo no autor uma "natureza inesgotável", contrapondo ao argumento de que "tudo já teria sido dito" sua afirmação de que "na verdade, nada foi dito ainda". (SCHLEGEL1967: 101)

Sob o ponto de vista do método de abordagem, o ensaio sobre Lessing utiliza, sem dúvida alguma,justificativas que provêm do conjunto dos procedimentos hermenêuticos, no sentido lato do termo. Schlegel constrói sua crítica sustentando-se sobre dois pontos fundamentais da hermenêutica moderna: o reconhecimento da “intenção do autor” e a consideração da fortuna crítica anterior, que Schlegel ora vai chamar de "impressão generalizada", "resultado comum da atuação conjunta de diversas influências e circunstâncias", passando por "crença cega", "hábito irrefletido", "tradição sagrada" até "finalmente quase uma lei inquebrantável". Presa que é dessa "impetuosa impressão", como poderia então a massa resistir-lhe, "interpondo-lhe apropriadamente a contrapartida intelectual, único meio capaz de permitir a construção do julgamento?" (SCHLEGEL 1967: 102)

Essa crença cega no gênio de Lessing tem, segundo Schlegel, consequências funestas para sua compreensão, pois "não raramente, o autor é contemplado sob uma luz completamente errônea". (SCHLEGEL 1967: 101-102)

A recorrência ao pensamento binário constituído por sobre a biografia do autor ("lado psicológico" da interpretação, em Schleiermacher) e à obra (em Schleiermacher, 
Maas, W. P. - Hermenêutica e anti-hermenêutica

o "lado gramatical", em sentido lato, da interpretação) é utilizada, por Schlegel, com o intuito de desfazer a opinio communis responsável pela "cegueira" vigente":

A crença cresce à medida que progride a fortuna crítica, o equívoco se consolida e se repete com o tempo, desaparecem os vestígios do melhor, muito e talvez o mais importante afunda no esquecimento. De modo que freqüentemente é preciso apenas um curto espaço de tempo para que a imagem se distancie de seu original até o limite do irreconhecível, e que entre a opinião dominante sobre um autor e aquilo que notadamente se encontra em sua vida e sua obra se crie a mais aguda contradição (SCHLEGEL 1967:102).

O ensaio constrói-se sobre uma estrutura de ziguezague, sendo que Schlegel apresenta conceitos firmados pela fortuna crítica, para logo depois desfazê-los como equívocos que seriam. $\mathrm{O}$ instrumento mais utilizado é certamente uma ironia moderada porque não completamente aparente. Em suas Charakteristiken [Características, 1797], em meio às quais se encontra o ensaio sobre Lessing, Schlegel apenas aponta para aquela ironia que corre à larga no ensaio sobre a ininteligibilidade. Aqui, trata-se menos de uma interpretação "gramatical" ou "filológica" da obra de Lessing do que de um texto dedicado a investigar

o aparecimento e construção gradativos da opinião dominante sobre Lessing [...], investigando-os até o menor detalhe [...], identificando com precisão [...] o todo constituído pela opinião geral, bem como as importantes divergências individuais, o que permitirá o estabelecimento de um ponto médio, capaz de lançar luz mais clara sobre o objeto por meio da breve alusão a alguns paradoxos. (SCHLEGEL 1967: 103)

Ao longo do ensaio, a hermenêutica de Schlegel parece sustentar-se muito mais como uma nítida hermenêutica do espírito, com pouca ou nenhuma atenção voltada à instância da letra e do procedimento filológico de fato.

Atribuindo a Lessing o epíteto de "espírito revolucionário", "fermentação poderosa" e de "violento abalo", Schlegel apressa-se em afirmar logo em seguida que “objetos revolucionários raramente são considerados sob uma perspectiva crítica"

4 Não por acaso, lembramo-nos aqui do sugestivo título do livro de Paul de Man, Blindness and insight (University of Minnesota Press, 1983). Ali, De Man propõe uma espécie de leitura corretiva de vários tópicos essenciais do pensamento filológico e filosófico moderno, apontando, maior parte das vezes, para a "cegueira" da crítica que o precedeu. 
Maas, W. P. - Hermenêutica e anti-hermenêutica

(SCHLEGEL 1967: 100). A "brilhante aparição" tornaria turva a visão dos que a contemplassem $^{5}$. Esse é o argumento básico sobre o qual Schlegel construirá sua interpretação de Lessing. Existe uma opinião crítica anterior firmada por sobre pressupostos equivocados. A essa é preciso, literalmente, destruir (abbauen):

A primeira impressão de uma manifestação literária não é só indeterminada ela também raramente é o efeito puro e simples da própria coisa, mas sim o resultado comum da atuação conjunta de muitas influências e circunstâncias. (SCHLEGEL 1967: 101)

Como resultado disso, muito freqüentemente o autor é apresentado sob uma "falsa luz". A impressão geral, predominante, torna-se "crença cega", "hábito irrefletido", "tradição sagrada" e, por fim, quase uma "lei inquebrantável". (SCHLEGEL 1967: 101). Se não fosse pela "crença sagrada", muitos poderiam ter considerado Lessing "nada mais do que um rematado místico, um cismador sofista e um pedantezinho" (SCHLEGEL 1967: 103). Schlegel propõe-se então a investigar a trajetória da construção da opinião vigente, de modo a desconstruí-la para depois a reconstruir da maneira "correta".

O primeiro julgamento sobre Lessing que deve ser refutado é: "Lessing foi um grande poeta" (no sentido lato, que inclui também a idéia de autor dramático). Aquele que não leu as obras em si, mas apenas as opiniões sobre elas, seria facilmente levado a considerar que as obras dramáticas seriam melhores do que "Erziehung des Menschheitsgeschlechts" [A educação da humanidade] e Freimaurergespräche [Diálogos dos maçons]. Em segundo lugar, Schlegel afirma que Lessing fora louvado como um "conhecedor quase perfeito e completo da poesia", como "gênio universal": "Endeusam-no, fazendo dele o sal da terra, e parecem crer que seu espírito não conheceu, definitivamente, quaisquer limites”. (SCHLEGEL 1967: 103). A despeito dessa amplitude que se atribui a Lessing, quase não se fala "do Witz e da prosa", que, segundo Schlegel, mereceriam ser chamados de "clássicos", em Lessing. Mais do que isso: uma teoria da prosa em língua alemã deveria começar a partir do estilo de Lessing (SCHLEGEL 1967: 104). Schlegel prossegue assim desautorizando a opinião vigente sobre o autor, apontando sempre para "os principais pontos de vista e rubricas sob os quais se julgou ou se quis dizer algo sobre Lessing": "sobre o que ele era de verdade, no

5 A metáfora utilizada lembra, mais uma vez, o título do livro de Paul de Man, Blindness and Insight. 
Maas, W. P. - Hermenêutica e anti-hermenêutica

todo, sobre o que queria ser e deveria se tornar, sobre isso parece que ninguém tem nada a dizer ou a julgar." (SCHLEGEL 1967: 108)

Schlegel passa então a criticar o método da abordagem aos textos de Lessing, censurando as opiniões que não se constituíram

segundo os diferentes níveis de sua [de Lessing] formação literária, ou segundo as épocas [fases] de seu espírito, com as diferenças de um estilo e tom individuais, ou mesmo segundo as direções e tendências predominantes na essência de seu ser [...], mas sim segundo o título de seus escritos, os quais não raramente, à guisa de registro, são ordenados de acordo com uma tipologia de gêneros que não quer dizer nada. (SCHLEGEL 1967: 108, grifo meu).

O parágrafo é significativo, pois congrega, na primeira parte do período ("diferentes níveis de formação do individuo", "fases de seu espírito", "diferenças individuais de estilo e direções predominantes de seu ser") um elenco de características que a hermenêutica moderna irá reconhecer como fundamentais para que o processo de interpretação tenha êxito. Nesse ponto, Schlegel encontra-se em total acordo com o pensamento de Schleiermacher, para o qual o processo de compreensão deve ocorrer sobre o pressuposto da congenialidade dos intelectos (ou espíritos), assim como sob o reconhecimento e mesmo a recriação das circunstâncias históricas da gênese da obra. Já a afirmação que sucede ao "mas sim" refuta os critérios (desta vez, claramente filológicos) da inserção da obra sob um gênero reconhecido. Isso prepara o terreno para a próxima afirmação, segundo a qual as melhores obras de Lessing "são um indivíduo por si só, uma criatura de um tipo único, peculiar", fato esse que "zomba de qualquer desejo de estabelecimento de limites pela critica". São obras que "não têm nem predecessores nem seguidores" (SCHLEGEL 1967:108). Com isso, Schlegel reedita a estética do gênio individual, contrapondo-a ao método hermenêutico capaz de inserir a obra única em uma série, legitimando o conceito de gêneros e subgêneros literários.

Cabe aqui a remissão aos cadernos sobre filologia (Zur Philologie) nos quais Schlegel desenvolve as relações entre filologia, história e crítica. Ali, Schlegel refere-se à necessidade do desenvolvimento de uma crítica a partir da "reavaliação histórica das relações entre uma hermenêutica filológica e uma crítica filológica” (MiCHEL 1982: 43, grifo meu). A centralização do foco sobre a história é evidente na concepção que Schlegel tem então da atividade interpretativa. As "fases ou épocas do espírito" e os 
Maas, W. P. - Hermenêutica e anti-hermenêutica

"diferentes níveis de formação do indivíduo" às quais Schlegel alude no ensaio sobre Lessing provêm dessa percepção: é preciso continuar insistindo no historismo, que é necessário à filologia. Logo a seguir, Schlegel associa essa percepção a uma fórmula hermenêutica: "Pelo espírito, contra a letra. Isso faz parte do historismo" (SCHLEGEL 1958, XVI: 55). Conclui-se daí que Schlegel compartilha com o Schleiermacher da moderna hermenêutica a percepção de que o horizonte histórico permeia o processo de compreensão do discurso do outro, e que as fases de formação do indivíduo, as "épocas de seu espírito", assim como o espírito da época, são variáveis que orientam esse processo. Por outro lado, em Schlegel, a hermenêutica do espírito confunde-se com a noção da individualidade e originalidade da própria obra, que ele opõe a qualquer sistematização ou normatização. Isso fica claro no ensaio sobre Lessing quando Schlegel refere-se à imaturidade daquele que

lê [a obra de Lessing] na a intenção iliberal de conhecer por meio dela as regras da poesia dramática, ou de adquirir conhecimento da poética de Aristóteles por esse meio, apaziguando assim a consciência; esse não tem o órgão para a individualidade e a genialidade dessa obra singular (SCHLEGEL 1967: 110-111).

Um claro exemplo de como Schlegel vê o processo hermenêutico, livre dos constrangimentos da normatividade, da sistematização e da necessidade de inclusão da obra em uma série, está na valorização da obra de Lessing mais por conta daquilo que Schlegel vai chamar de "Winke und Andeutungen", "acenos e alusões", do que pelo reconhecimento de uma sólida carreira literária e ou crítica:

O mais interessante e o mais profundo em seus escritos são os acenos e as alusões, o mais maduro e o mais perfeito são fragmentos de fragmentos [Brüchstücke von Bruchstücken]. O melhor do que Lessing diz é algo, entre o adivinhado e o inventado, que ele lança por meio de meia dúzia de palavras prodigiosas, cheia de força, espírito e sal: palavras, nas quais os pontos mais obscuros são, no âmbito do espírito humano, como se iluminados repentinamente por um raio, o mais sagrado expressando-se de maneira extremamente ousada e quase sacrílega, ao tempo em que o mais vulgar se expressa de maneira extravagante e caprichosa. Suas orações [Hauptsätze] estão lá, como axiomas matemáticos, sem desmembramento [Zergliederung] ou demonstração e seus arrazoados mais coesos e concludentes são, na maior parte das vezes, apenas uma cadeia de associações espirituosas." [witzige Einfälle] (SCHLEGEL 1988: 215). 
Maas, W. P. - Hermenêutica e anti-hermenêutica

Curiosamente, o comentário que Schlegel faz sobre Lessing (de caráter "filológico", embora desprovido de comprovação textual) cabe à perfeição como descrição da obra do próprio Schlegel. É possível afirmar que Schlegel aplica aqui, de maneira invertida, algo que anunciara nas primeiras páginas do ensaio sobre Lessing: a intenção de submeter o próprio texto de Lessing às leis que este estabelecera para o julgamento dos grandes mestres da arte e poetas (SCHLEGEL 1967:108). Schlegel parece julgar a obra de Lessing projetando sobre ela seu próprio estilo de composição. Por fim, Schlegel afirma que "é de se esperar que, de um homem como esse [Lessing], uma conversa breve possa ser muita mais instrutiva, e conduzir muito mais longe, do que uma longa obra." Linhas antes, Schlegel já afirmara que "uma conversa viva teria muito mais poder e força do que a palavra escrita."

Essa concepção irá se desenvolve em toda a sua amplitude e consequências no ensaio da ininteligibilidade, que se pode considerar o coroamento do pensamento hermenêutico de Schlegel. Ali, convergirão tanto os pressupostos que compartilha com Schleiermacher quanto se dará livre vazão ao furor anti-hermenêutico, em associação com a ironia e a noção de linguagem em tempo real, que privilegia o momento da fala entendida como performance.

\section{O ensaio sobre o Meister}

Publicado na Athenäum em 1800, ano dos mais produtivos para a compreensão do Schlegel "hermeneuta", o Übermeister foi muitas vezes reconhecido como modelo de crítica exemplar.

O elogio é de fato merecido, pois é um dos poucos trabalhos críticos de Schlegel em que ele associa as intuições do "espírito" ao conhecimento filológico, de acordo com os princípios mais ortodoxos da hermenêutica de Schleiermacher. Schlegel comenta o romance de Goethe, seguindo minuciosamente a seqüência dos capítulos, atento aos contrastes, à relação das partes com o todo e as estratégias do autor/narrador para evidenciar o caráter das personagens. Trata-se de uma análise filológica ainda hoje atual, reveladora mesmo, capaz de trazer à luz os mecanismos de composição do romance goethiano e abrir caminho para uma linha de interpretação até então inédita, aquela que reconhece a ironia que espreita por detrás do projeto de formação do 
Maas, W. P. - Hermenêutica e anti-hermenêutica

protagonista e o deslocamento deste da posição de principal pilar da arquitetura narrativa.

Pode-se aplicar ao texto do Übermeister o mote compartilhado por Schlegel e Schleiermacher no que concerne a compreender um autor tão bem quanto - ou melhor do que - ele compreende a si mesmo.O próprio Goethe referira-se certa vez a seu protagonista como um armer Hund, um pobre diabo, indicando assim aquela que será a linha determinante no ensaio de Schlegel.

Logo nas primeiras páginas, Schlegel apresenta a perspectiva que permitirá emergir essa leitura:

\footnotetext{
É bom e é necessário entregar-se inteiramente ao efeito de uma obra, permitir ao artista que faça conosco o que lhe aprouver, deixando que a reflexão confirme o sentimento apenas em determinados pontos singulares, elevando-os ao pensamento e, onde ainda persistir a dúvida ou a controvérsia, decida e complete o sentido. Isso é o primordial e o mais importante... É preciso que nos elevemos acima de nossas preferências e que sejamos capazes de destruir em pensamento aquilo que veneramos (SCHLEGEL 1988: 160, grifo meu)
}

O parágrafo concentra duas proposições em princípio antitéticas, como é freqüente em Schlegel: a primeira parte propõe uma recomendação de leitura que sinaliza para o predomínio de uma fruição quase intuitiva, a passo que a segunda preconiza o distanciamento do eu em relação a si mesmo, princípio da ironia schlegeliana.

Essa proposição progride ao longo do ensaio até culminar na percepção de que no romance de Goethe não se cuidou exatamente da formação de Wilhelm Meister: "Nós vemos também que estes anos de aprendizado querem e podem antes formar qualquer outro que não o próprio Wilhelm em um hábil artista e cidadão capaz." (SCHLEGEL 1988: 168).

O método de Schlegel, derivado do princípio do distanciamento, permitirá que chegue à "intenção do artista" de acordo com a concepção hermenêutica da congenialidade de intelectos:

Deixemo-nos, pois, arrancar do encantamento exercido pelo poeta, depois que, de boa vontade, nos deixamos prender por ele; de preferência espreitemos, procurando por aquilo que ele esconde de nossos olhos ou que não quis mostrar logo da primeira vez, e que certamente faz dele um artista: as intenções secretas, 
Maas, W. P. - Hermenêutica e anti-hermenêutica

que ele persegue em silêncio, e que não somos capazes de pressupor, quando confrontados ao Gênio, cujo instinto se torna arbítrio. (SCHLEGEL 1988: 160)

A expressão "intenção do autor" [Absicht des Autors] ocorre repetidas vezes no texto, sempre associada a uma descoberta que deve trazer maior clareza sobre o objeto analisado, ainda que eivada de uma certa ironia:

Foi tão forte a intenção do artista de não apresentar uma doutrina incompleta da arte, ou melhor, de oferecê-la em exemplos vívidos e perspectivas variadas [...], que essa intenção pode induzi-lo a uma apresentação de caráter episódico [...]. (SCHLEGEL 1988: 160)

Schlegel alude aqui a uma possível "falta de organicidade" no romance de Goethe, manifesta nos capítulos de natureza episódica e em excursos freqüentes na narrativa. Dessa forma, repete um princípio defendido também pelo Schleiermacher maduro, o da exigência de totalidade da obra.

Em outros trechos, Schlegel semeia já, manifestadamente, o gérmen da ironia, instaurando já no Übermeister o registro que será a tônica do ensaio sobre a ininteligibilidade:

Não nos deixemos enganar pelo fato de que o poeta toma as pessoas e os acontecimentos de modo tão leviano e caprichoso e menciona o protagonista quase sempre com ironia, parecendo sorrir das alturas de seu espírito; trata-se, para ele, da mais sagrada seriedade. (SCHLEGEL 1988: 161)

Schlegel está atento aos contrastes entre o estilo baixo e o elevado que convivem no romance de Goethe, o que lhe permita reconhecer a presença da ironia sempre à espreita:

Esse aspecto cômico não se constitui, absolutamente, de partes que sejam finas, delicadas ou nobres. Ao contrário, muito pertence àquele tipo de coisa sobre a qual a gente se ri com vontade e de modo vulgar, como o contraste entre as mais belas expectativas e o péssima hospedagem. ${ }^{6} \mathrm{O}$ contraste entre a esperança e aquilo que efetivamente se dá, entre a imaginação e a realidade desempenha

6 Menção ao livro do romance de Goethe, no qual a trupe teatral espera ser alojada condignamente no castelo do Conde e encontra uma verdadeira pocilga. 
Maas, W. P. - Hermenêutica e anti-hermenêutica

aqui de fato um papel importante; a realidade impõe seus direitos com impiedoso rigor [...]. Um tal frescor das cores, esse colorido infantil, [...] essa leviandade espirituosa e essa malícia ligeira têm algo de [...] muito delicado e de muito tênue para que a letra pudesse reconstruir e reproduzir sua impressão. Só àquele que pode ler em voz alta e que a entende completamente, a ironia se entrega, ironia que paira por sobre a obra inteira, mas que aqui se faz de preferência altissonante e claramente perceptível àqueles que têm o órgão para percebê-la. Essa aparência de dignidade que se ri de si mesma [...], esses aparentes desleixo e as tautologias [...], essa disposição altamente prosaica em meio à disposição poética do assunto, esse bafejo de pedanteria poética em ocasiões extremamente prosaicas frequentemente têm a ver com uma única palavra, até mesmo com um acento. (SCHLEGEL 1988: 164)

O trecho é fundamental para que se ilumine a concepção de ironia que tem o próprio Schlegel: ao reconhecer, "hermeneuticamente", a intenção do autor, Schlegel legitima-a por meio de um recurso, digamos retórico ou prosódico (performático, diríamos hoje). Apenas a leitura em voz alta (vorlesen), a modalização verbal do texto goethiano permitiria aos mais desavisados o reconhecimento dessa ironia. Schlegel alude aqui, quase desapercebidamente, à concepção de ironia como performance, que terá livre desenvolvimento no ensaio sobre a ininteligibilidade. Alude também a uma espécie de elite composta por aqueles a quem a ironia se dá a conhecer (Cf. MAAS 2008: 170).

Em resumo, é possível afirmar que nos dois ensaios comentados, o texto sobre Lessing e a resenha sobre o romance de Goethe, operam conceitos reconhecidamente hermenêuticos (intenção do autor, congenialidade, hermenêutica do espírito em contraposição à filologia como hermenêutica da letra, conjunção entre crítica, hermenêutica e história). Não se pode, portanto, afirmar que o repertório da moderna hermenêutica, como a compreendia Schleiermacher, tenha sido estranho a Schlegel. Ao contrário, os dois ensaios acima comentados legitimam e comprovam a familiaridade com o campo e mesmo possíveis contribuições a esse repertório, como quer Körner. No entanto, é preciso deixar claro que o processo de compreensão do discurso do outro, em Schlegel, escapa a qualquer sistematização e normatização. A ênfase concedida à individualidade da obra, que não permite sua inserção em uma série como a constituída sobre a idéia de gêneros literários, a crença de que o entendimento da intenção do outro se dá mais por meio de uma afinidade quase mística ente os intelectos do que por meio da investigação filológica, culminando no entendimento da ironia apenas por alguns iniciados, acabam por afastar Schlegel do projeto hermenêutico de Schleiermacher, o 
Maas, W. P. - Hermenêutica e anti-hermenêutica

que lhe valeu, por parte deste, anos depois de sua morte, o epíteto de "gênio paradoxal", em um discurso de 1829.

\section{Referências bibliográficas}

Behler, E., Anstett, J-J. e Eichner, H. Kritische Friedrich Schlegel Ausgabe. Paderborn, München, Wien, Zürich: Ferdinand Schöningh, 1958.....I-XXXV.

FRANK, M. Einführung in die frühromantische Ästhetik. Vorlesungen. Frankfurt a.M.: Suhrkamp, 1989.

. Einleitung. In: Ders. (Hg.) Hermeneutik und Kritik. Frankfurt, Suhrkamp, 1977.

HÖRISCH J.. Die Wut des Verstehens. Frankfurt, Suhrkamp, 1988.

KÖRNER, J. (Hg.). Friedrich Schlegels Philosophie der Philologie. In: Logos 17, 1928, 172.

MAAS, W. P. M. D. Ironia e performance no Primeiro Romantismo Alemão. In: artefilosofia 4, 2008, 166-174.

SCHLEGEL, F. Über die Unverständlichkei. In: Kritische Ausgabe II. Paderborn, Schöningh, 1967.

In: Behler E. (Hg.). Schriften und Fragmente. München: Carl Hanser Verlag, 1956.

Kritische Schriften und Fragmente. In: BEHLER E., EICHNEr H. (Hg.). Paderborn, München, Wien, Zürich, Ferdinand Schöningh, 1988. v. 1-2.

SCHLEIERMACHER, F. Reden über die Religion. Berlin, 1799.

SCHLEIERMACHER, F. In: FrANK, M. (Hg.). Hermeneutik und Kritik. Frankfurt, Suhrkamp, 1977. 